\title{
The Path towards a "Good City": A Discussion on (In)civility
}

\author{
By Guliz Mugan*
}

\begin{abstract}
There is a growing interest on the significance of civility and incivility in contemporary urban life. The blurred definitions regarding the term incivility are needed to be highlighted since they have the potential danger in leading some unintended policy implications that may result in exclusion and inequalities in urban field. This paper aims to focus on the issue of (in)civility within city context by focusing on the varied definitions and meanings of civility and incivility, through the conceptual and empirical evidences from different urban settings. Within the framework of the descriptive and exploratory researches, the goal of the study is to formulate more precise questions about incivility as well as refine issues about the consequences of incivility for different individual groups. Therefore, strategies to tackle incivility and to promote civility within the city context are discussed by giving particular attention to interventions in terms of policy implications. Hence, the path towards a good city and active citizenship is tried to be traced by emphasizing unintended consequences of those policies such as exclusion of certain groups and resulting inequalities.
\end{abstract}

Keywords: Civility, City Context, Crime, Incivility, Security.

\section{Introduction}

In recent years, there seems a growing interest on the vital place of civility and incivility in contemporary urban life (Boyd 2006, Fyfe et al. 2006, Philips and Smith 2006). However, there seem many contradictions resulting from broad definitions and commonsense understandings of many connotative meanings of terms such as civility/respect/politeness and incivility/anti-social behavior/ criminality/rudeness (Amin 2006, Boyd 2006, Fyfe 2005). Those blurred definitions are significant to emphasize, since they have the potential danger in leading some unintended policy implications that may result in exclusion and inequalities in urban field (Al-Haj 2002, Bannister et al. 2006, Crawford 2006).

This paper aims to focus on the issue of (in)civility and city within the framework of four headings, while following the goals of exploratory and descriptive researches. In that manner, the goal is, firstly, to become familiar with basic facts and concerns of incivility; secondly, to develop a well-grounded mental picture of incivility researches in different urban settings; and thirdly, to determine the possibility of doing additional research and give a sense of direction for further explanations and researches about future of cities and citizenship. Accordingly, the first heading aims to discuss the varied definitions and meanings of civility and incivility in consideration with the relationships between (in)civility and the city. While discussing those multiple and complex

\footnotetext{
${ }^{*}$ Associate Professor, Department of Interior Architecture, Okan University, Turkey.
} 
meanings of the terms civility and incivility, some related notions such as respect, equality, anti-social behavior, criminal acts, disregard, exclusion are also on the agenda of elaboration. The second heading aims to look through the conceptual and empirical evidences of some researches that have been conducted concerning the experience of civility and incivility within different urban settings in city life including, shopping malls, neighborhood spaces, transport hubs, nonmetropolitan geographical areas, etc. Third aim of this paper is to demonstrate strategies to tackle incivility and to promote civility within the city by giving particular attention to interventions in terms of some policy implications by governments and citizens. And finally, the fourth aim is to focus on the unintended consequences of those policies such as fear and hostility against differences in the city, exclusion of certain groups and resulting inequalities. By this way, the path towards a good city and active citizenship is tried to be traced.

\section{Varied Definitions and Meanings of Civility and Incivility within the Context of City}

Concerns with civility in the city context is nothing new and it is very much bounded with street behavior that can range from the role of the built form of a city to linkages between social interaction at street level and to broader geopolitical developments (Fyfe et al. 2006). "Psychologists, sociologists, historians and geographers have been questioning the role of urban organization in the emergence and definition of civility or its opposite, incivilities" (Félonneau 2004: 46). Civility as a paradoxical concept also has paradoxical associations with city. On the one hand, urban life has assumed to be necessary for the development of civility and the word "urbanity" has been mentioned together with the word "civility" (Boyd 2006). "Already in the $16^{\text {th }}$ century, Erasmus (1528) conceived civility as a strategy for distinguishing between the urban milieu and the peasant crudity and the barbarian instinct" (cited in Félonneau 2004: 46). On the other hand, "celebrations of civility and the city have existed alongside deep anxieties about the incivility of urban life" (Fyfe et al. 2006: 854). For instance, Robin et al. (2007: 56), by referring to the researches of Korte (1980) and Milgram (1970), state that "urban living incurs social withdrawal behavior, reduces helping behavior and destroys civility". In order to cope with this contradictory associations with the issue of civility within the context of city, it is necessary to overview the variety of definitions and meanings concerning (in)civility.

According to Fyfe et al. (2006) one distinction for the definition of civility is that between "proximate" and "diffuse" civilities. "Proximate" civility is commonly used as politeness or absence of "rudeness" in personal interactions. This understanding of civility is related to both our verbal and non-verbal communication; physical interaction, presentation and appearance; body or language (Fyfe et al. 2006, Philips and Smith 2006). According to Boyd (2006), such a definition of civility reduces it to formal connotations in the form of manners, politeness, and courtesies of face-to-face interactions. These formalities include being respectful and sociable through speaking in a sympathetic tone, using correct titles and phrases, behaving in an appropriate manner, etc. Félonneau 
(2004), by associating civility with showing respect to codes and interaction rituals, emphasizes the formality aspects of civility. Therefore, according to her, incivility is related to the act of non-respect or aggression towards others and towards environment.

The term "diffuse" civility is a much broader understanding of civility regarding the impacts of our behaviors on others. Diffuse civility brings together the responsibility of the effects of our actions on others, on care for spaces regardless of the necessity of co-presence (Fyfe et al. 2006). In this scope, what Hunsberger et al. (2005) mentioned concerning civility as one of the sustainability goals for the environmental assessment, together with ecological integrity and democracy can be categorized under diffuse civility. According to Boyd's (2006: 864) classification of civility, diffuse civility can denote "a sense of standing or membership in the political community with its attendant rights and responsibility". This kind of civility is formulated through civil rights or civil obedience. However, Boyd (2006: 865) carries these two distinct definitions of civility one step beyond and claims that as we are all part of a moral public, the practice of civility clearly "generates a sense of inclusivity and moral equality" for all of us. According to him, civility is about active and moral relationships between people. Amin (2006) shares a similar understanding of civility with Boyd by having an emphasis on solidarity and the politics of living together. He highlights the importance of care and regard for a civil contemporary city, which is in the direction of urban disregard, intolerance and self-interest.

The terms disregard and disrespect are mainly used together with the term incivility leading to different forms of crime (Medway et al. 2016, Robin et al. 2007). Another term that is used to define incivility is "anti-social behavior" that should be tackled to promote civility and this term has started to be placed within law and order policy discourses (Flint and Nixon 2006, Fyfe et al. 2006). Incivility in the form of anti-social behavior posits that incivilities erode social ties and eroded social ties result in crime and lead cities to cities where citizens are very vulnerable to crime (Brown et al. 2004).

As it is discussed in this section, the issue of (in)civility has many paradoxes and complex meanings within the city context. It may involve both responsibilities of individuals towards each other and towards the environment and the city of which they are a part of. In the light of those complex variations in definitions, the consequences in promoting civility and reducing incivility within the cities can also vary regarding the nature of civility that we wish to create. Before moving to those consequences, which can be related with public liberties, equality and citizenship, to have a better understanding of the variations and complexities of (in)civility in cities, in the next section, the experience of the issue of (in)civility in different urban settings is discussed in the light of some researches.

\section{Experience of (In)Civility in Different Urban Settings}

Different forms of incivilities can be encountered within the city context. If we associate incivility with "rudeness", what we look for as incivilities are beyond the criminal acts such as graffiti, burnt-out cars or homicides (Brown et al. 2004, 
Philips and Smith 2006). According to study of Philips and Smith (2006) we can encounter with a rude stranger who tries to push into queues at the ATM, who use bad language on the train, etc. On the basis of past behaviors in interpersonal relationships, certain social groups are marginalized and considered as incivil encounters: the unemployed, the homeless, and the young people who are seen as disrespectful or disruptive (Salcedo 2003, Wakefield 2005). Wakefield (2005) cites the arguments of Norris and Armstrong (1999) and McCahill (2002) that emphasize how those groups of individuals are labeled as people engaging in "anti-social" behavior, people behaving "differently" from the norms of the society. However, the research of Philips and Smith (2006: 898) indicate that "'respectable' people such as middle-aged elderly were the most likely perpetrators of an everyday incivility, not minority youth".

As Philips and Smith (2006: 898) indicated, "consumption spaces and transport nodes were the most likely venues for the incivil encounter and not the residential neighborhood". Shopping malls, where diverse people come together, have become the heart of public and social life for many people, so, the maintenance of civility within those spaces gains significance (Staeheli and Mitchell 2006). However, different than many other urban settings, trying to maintain civility within mall spaces brings strict regulations of malls' institutions, functions and users into agenda with an intend to form civility for a privileging community. As Oc and Tiesdell (1997: 14) pointed out, newly-built, high quality, environmentally-controlled shopping malls provide "comfort and security, while their single management permits a uniform maintenance of standards and quality". This process of privatization allows for a sort of classification that separates the privileged from the undesirables (Abaza 2001, Wakefield 2005). In other words, within this scope, tolerance for difference has been traded off for achievement of civility which has the consequences in terms of exclusion and inequality, which is analyzed in detail in the fourth section.

By highlighting the increase crime and fear of crime in recreational settings, McCormick and Holland (2015) mention about urban parks where some strategies are used to reduce incivilities in order to reduce crime rates. According to their study, mostly faced incivilities in urban parks are trash, graffiti, insufficient signage system and lighting. The most widely used strategies are related to removal of trash and graffiti and improving lighting and signage system. Stationing of uniformed park personnel, security cameras or park watch citizen groups are indicated to be less utilized approaches for reducing incivilities.

Another urban setting that should be overviewed, in which incivilities are experienced and regulated is the neighborhood spaces. Urban neighborhoods are important spaces for political struggle. Kennett and Forrest (2006: 713) states that "the neighborhood remains as a key site in the repoliticisation of the city, the arena from which new forms of citizenship, solidarity, cohesion and patterns of integration emerge". Researches demonstrate that there is a relationship between the perception of incivilities within neighborhoods and the feeling of insecurity for citizens (Brown et al. 2004, Lee 2006, Valera and Guardia 2014). According to the study of Robin et al. (2007), incivility in neighborhoods is associated with sharing of public spaces by different users. In another study, Valera and Guardia 
(2014) indicate that perceived insecurity and fear of crime in a working-class neighborhood of Barcelona is mostly related to environmental features, personal variables and social representation of unsafe places within the neighborhood. Moreover, according to them urban social identity and residential satisfaction are also significant variables for perceived incivilities.

As Lee (2006) noted in her investigation, the context, in which the personal interactions are embedded turns the issue of civility into a precarious and fragile consideration. For instance, as her study pointed out, although the civility is the norm, the racial and socio-economic context within which the interactions are located, preclude the efforts to maintain civility and leads to emergence of protest motivations. In another study, Reisig and Cancino (2004) pointed out that citizens living in economically disadvantaged neighborhoods are more likely to perceive their immediate surroundings in more negative terms by indicating higher levels of incivilities, where the measure of perceived incivility included items such as noisy neighbors, public drinking, drug dealing, rundown building and litter. Whereas, citizens living in residential units report fewer incivility problems. After an overview of civility and incivility experiences in different urban settings, in the followings section, interventions and policy implications to tackle incivility and to promote civility are discussed through their intended consequences.

\section{Interventions to Tackle Incivility and to Promote Civility}

While discussing the varied definitions and meanings concerning (in)civility, it has been mentioned that incivility leading to different forms of crime may result in engendered fear, insecurity and deterioration of the social order for those living in cities, i.e., citizens (Philips and Smith 2006, Robin et al. 2007). According to the "broken window" thesis of Wilson and Kelling (1982), cited in both Fyfe et al. (2006) and Philips and Smith (2006), disorder and disregard which can be used to address incivility lead to engendered fear against increasing crime among "law abiding" citizens that may in turn result with retreatment from public interaction. For instance, the study of Medway et al. (2016) provides the evidence for the causal relationship between seeing litter in the environment and perceptions of incivilities and crime prevalence at the individual level. However, as their study as well as the study of Philips and Smith (2006) demonstrated that such a thesis is problematic and has some different points to be discussed. Accordingly, the assumption limited itself to a narrow application of criminology; whereas incivility is needed to be explored in full range in addition to its criminal basis; that is by reducing it to everyday personal interactions within variety of settings with a broader perspective. Therefore, as Philips and Smith mentioned (2006: 898), "fear and retreatism were not common responses to incivility". Moreover, what Medway et al. (2016) emphasized is that removal of some physical incivilities such as litter which can be perceived as a sign of crime prevalence, is not the job of police forces, but in fact to be the job of municipal agencies. Within this scope, it is possible to argue that on the contrary to the thesis of retreatment, citizens and governments intervene with policy implications to 
promote civility and to tackle incivility.

As Lees (2004) observed, "the politics of fear is driving the growth of private police forces, gated communities and public surveillance antithetical to the old civic virtues of civility, security, tact and trust inculcated by mingling with strangers in the city" (cited in Fyfe et al. 2006: 854). Use of surveillance in shopping malls in order to prevent disorder and disregard serves also the aim of creating a "purified" urban experience for civility (Koskela 2000, Sibley 1995).

Interventions for civility policy implications can work in two separate levels: civil society (at the government level) and individual behavior (at the citizenship level) (Bannister et al. 2006). There are different implications of policies that intervene to civility promotion concerning these two levels.

Presence of incivilities as an important justification for policies like zerotolerance in cities like New York can be categorized under intervention at the governmental level. As another strategy at this level to tackle anti-social behavior, Flint and Nixon (2006) discuss the role of public housing agencies in UK. According to them "discourses on anti-social behavior in the UK are embedded within a wider politics of conduct based around concepts of citizenship, selfregulation, welfare conditionality, obligations to communities and rights and responsibilities" (Flint and Nixon 2006: 939). The regulations such as Anti-social Behavior Orders, Acceptable Behavior Contracts and tenancy arguments are representative of interventions ${ }^{1}$ of various actors in the governance of civility (Flint and Nixon 2006).

Concerning the interventions to policy implications at the government level, the studies of Bannister et al. (2006), Brannan et al. (2006) and Fyfe (2005) can also be given as examples, through which the concern of UK government to promote civility with orders like "anti-social behavior orders" are highlighted by giving special emphasis on different organizations and how they contribute to "the reinvigoration of civil society by fostering the development of social capital and citizenship" (Fyfe 2005: 552). Brannan et al. (2006) by reviewing the aims and practices of active citizenship in UK, highlight the key concepts concerning government interest in civic-ness and developed policy agenda in crime, regeneration and housing, education, health and local government. In addition, Crawford (2006), by exploring the emphasis upon the policing of incivilities, examines the role and contribution of neighborhood wardens in fostering social order in deprived neighborhoods. As he pointed out, government expects wardens to perform variety of roles, including patrolling, maintenance of visible presence, tasks related to environmental management and stimulation of community engagement. In other words, those wardens having sufficient authority with political expectations act as agents of social control in neighborhood life to promote civility.

According to Brown et al. (2004), in order to improve neighborhoods and make them truly viable, it is necessary to focus on incivility reduction. And the interventions to reduce incivility lies in creating positive bonds between people and places; bonds of place attachment. Trials to enhance sociability or

\footnotetext{
${ }^{1}$ In Turkey, Law of Offences - 'Kabahatler Kanunu' which is revealed by the Ministry of Interior, General Directorate of Security can be declared as one of these regulations.
} 
guardianship, or programs such as Neighborhood Watch, or neighborhood cleanup campaigns are stated as the interventions that work at the citizenship level with an aim to enhance social bonds of place attachment in order to tackle incivilities in neighborhoods. On the contrary to this assumption, Crawford (2006: 957) argues that the way towards civility passes from "fostering weak social ties rather than strong bonds of 'togetheness'". Such an individualistic determination makes the promotion of civility argument move to interventions at the individual level.

Concerning the interventions at the individual or citizenship level, it is possible to look at the self-responsibility of each citizen to promote civility within the city context they live. Citizen-based monitoring and the interests of sustainable livelihoods using local knowledge at the citizen level can be considered to promote diffuse civility (Hunsberger et al. 2005).

Interventions at the individual level to promote civility depend on different motivations of people. Their motivation might be a result of their moral outlook or might be based on cost-benefit weightings (Brannan et al. 2006). Such kinds of 'politics of behavior' has prompted a shift from state-based citizenship to a more individual-based citizenship and citizen rights (Basok 2004). What Foucault discussed in his famous study, Discipline and Punish, is to demonstrate the importance of self-regulating subject in the light of his understanding on knowledge, power, individual body, state, and society. He implicitly describes the Panopticon, as an efficient regulating mechanism which has started at the state and governmental level, and by moving beyond this, which has become a self-regulating tool that works at the societal level for controlling multiplicity of individuals with a minimum cost to tackle disorder and anti-social behavior with a civil society concern (Foucault 1979).

Although many different interventions at both governmental and citizenship level can easily be clarified and be analyzed around a logical framework concerning their possible intended consequences to promote civility and to tackle incivility with different emphases and by using different regulations and tools, there might exist some unintended consequences of those interventions and regulations. Since the issue of (in)civility has many ambiguities starting with its definition within the scope of diversity and difference of urban life, it is difficult to deploy it into policy discourse. In the following section, it is aimed to focus on those possible unintended consequences of promoting civility concerning exclusion, equality/inequality, feeling of insecurity and rights of citizen.

\section{Unintended Consequences of Policy Implications of (In)Civility}

According to contemporary moral panic and belief, incivility results from behavior of certain social groups and communities (Fyfe et al. 2006, Philips and Smith 2006). Since the increasing difference and diversity of urban life are viewed as threatening, the policy implications to tackle with this threatening fear have possible undesired consequences for certain groups of individuals. Exclusion and intolerance of difference are not new in the spatial and social organization of city life (Malone 2002). Al-Haj (2002) states that pluralistic 
societies having social and cultural difference and diversity face with the question of how to deal with this issue and to build a shared civility among its different nations, ethnic, religious and social groups.

Incivility, which is mainly defined as anti-social behavior, rudeness, disorder and disregard, has been indicated as having close connections with difference and diversity within the city context (Lee 2006, Reisig and Cancino 2004, Robin et al. 2007). Concerning the policy implications to promote civility, which are discussed in the previous section, it seems that it is tried to be achieved through the exclusion of incivilities and the unrespectable in order to secure the public realm for the respectable and this makes city even more hostile to difference (Fyfe et al. 2006). In other words, policy implications through interventions are trying to trade off difference and diversity within city for achieving civility. Zero-tolerance policing is a good example that works in this manner by including "the paradox of imposing civility through coercion or at least threat of it" (Crawford 2006: 854). Similarly, neighborhood wardens and security guards patrolling within the malls seem to be drawn in law enforcement activity by undermining their role on community development work and tackling incivility (Crawford 2006, Fyfe et al. 2006). Moreover, the promotions that are anticipated to create positive bonds between people and places and interventions which are tried to be regulated to enhance sociability or guardianship in certain exclusive neighborhoods (Brown et al. Perkins 2004), or some gangs and associations in non-metropolitan or in economically and ethnically disadvantaged neighborhoods (Lee 2006, Reisig and Cancino 2004) can be argued as contributing little or nothing to civility; they are bearers of incivility (Boyd 2006, Crawford 2006, Fyfe et al. 2006). Self-regulating promotions of civility such as surveillance in the mall space which aims to tackle incivility through self-disciplining of individual users may threaten dignity and autonomy and may lead to feeling and perceiving insecurity, embarrassment and exclusion (Goold 2002, Koskela 2000). Hence, the insecure, embarrassed and angry citizens can be expected to promote incivility, rather than civility.

As Boyd (2006) agued, there is a great danger in effort to create civility which results in hastening of its departure. In other words, it can be possibly argued that interventions to promote civility might lead to exclusion, intolerance of difference and feeling of insecurity, which may in turn result with further incivilities, anti-social behavior, disorder and disrespect (Amin 2006, Bannister et al. 2006). Patrolling and commanding police officers, security guards, wardens, regulations such as zero-tolerance policing and panoptic authoritarianism of urban governance can only increase the tension among citizens and trigger inequality resulting from exclusion and this may only come up with more "promoted incivility" (Amin 2006, Boyd 2006, Crawford 2006, Bannister et al. 2006). As Cohen (1985: 201) pointed out:

\footnotetext{
"the resultant forms of control will be less noteworthy for their effects on crime than their intrusive side-effects on ordinary citizens: a retreat into fortress living; streets abandoned to outlaws; inconvenience and erosion of civil liberty"
} 
After discussing the possible unintended consequences of interventions of policy implications in relation to civility and incivility, on the way to a good city, now it becomes necessary to emphasize more innovative and radical thinking in promotion of civility and in protections of citizen rights and civil liberties.

\section{Conclusion}

In this paper, four main issues was addressed concerning the issue of (in)civility within the context of city by focusing on the goals of descriptive and exploratory researches. Accordingly, the goal of the study was to formulate more precise questions about incivility as well as refine issues about the consequences of incivility for different individual groups. First of all, complexity and variations in defining civility and incivility and their relationships with the form of urbanity was underlined. The dangers in relating civility with broader terms and definitions and only with criminal acts, without dealing the daily aspects of encountering incivility was pointed out. Secondly, within the scope of those complexities, experience of civilities and incivilities in different urban settings was analyzed. In addition, varied neighborhood settings, shopping malls, transport hubs, etc. were given as examples of urban settings that we could encounter with incivilities in respect to different meanings that we attached to them according to variety of social interactions that we are a part of. Thirdly, interventions to tackle incivility and to promote civility was discussed in terms of various policy implications in the form of governmental and citizenship level. After that, in the fourth part, the possible unintended consequences of those policy implications, besides those of intended ones to promote civility was emphasized.

Threats to the civil liberties of those who have done little wrong with interventions of policy regulations such as zero-tolerance policies resulting from blurred definitions of (in)civility can be categorized as unintended consequences in promoting civility. According to this, what is tried to be considered is to imply policies that give attention to determine whether civility is really declining and/or all incivilities are really damaging, and are really threats for interpersonal relations in everyday life. In this respect, it is anticipated to prevent the promulgation and implication of policies and regulations that leads to exclusion, inequality and feeling of insecurity.

Therefore, to make interventions of policy implications to meet with their intended consequences, i.e., to reduce incivility and to promote civility, much more innovative and radical thinking in this area is needed. First of all, it is needed to determine the framework in defining (in)civility within the city context. It is important to move meaning attachments of incivility beyond criminal acts. It is necessary to analyze the issue of (in)civility within the scope of daily encounters. Secondly, it is needed to look beyond the assumption, which advocates that incivility results from the behaviors of certain social groups and communities; rather incivility should be linked to the entirety of urban experience. Thirdly, positive and negative consequences in dealing with diversity and difference within different urban settings having different contextual structures 
should be determined. For instance, it is important to differentiate the disorder and anti-social behavior that is emerged out of lack of familiarity, communication, exclusion and inequality within a disadvantaged urban setting from an intentional rudeness and aggression within a more advantaged setting. For the first case, it is important to consider the fact that anti-social behavior may stem from the exclusion and intolerance of difference in the society against those citizens and this may lead to perception and definition of those behaviors under the heading of incivility, which may in turn lead to interventions of strict policies. And those strict policies may also lead to more "perceived incivilities". In order to prevent such a vicious circle, what should be paid attention is to move beyond the short-term success or failures of interventions of policy implications to tackle with incivility, to the long-term impact and quality of social interactions (Fyfe et al. 2006). The "good city" that Amin (2006) has associated with solidarity, care, regard, tolerance for difference, is the model that should be achieved. In order to achieve this, "the politics of living together" should be succeeded by giving emphasis on infrastructure of various software systems, surveillance systems and transport systems which make the urban life possible without making citizens feel insecure or under control (repair), by drawing obligations on a solidarity of human rights (relatedness), by including, not by excluding, those viewed as threats to civility (rights) and by promoting individual and cultural heterogeneity (re-enchantment) (Amin 2006). Although it seems that this model is offering "a practical urban utopianism based around four registers of solidarity" (Amin 2006: 1009), it also draws an applicable path towards a good city that should be traced concerning, justice, ethics, moral relations, tolerance of difference and responsibilities of active citizenship.

\section{References}

Abaza M (2001) Shopping malls, consumer culture and the reshaping of public space in Egypt. Theory, Culture \& Society 18 (5): 97-122.

Al-Haj M (2002) Multiculturalism in deeply divided societies: The Israeli case. International Journal of Intercultural Relations 26: 169-183.

Amin A (2006) The good city. Urban Studies 43(5/6): 1009-1023.

Bannister J, Fyfe N, Kearns A (2006) Respectable or respectful? (In)civility and the city. Urban Studies 43(5/6): 919-837.

Basok T (2004) Post-national citizenship, social exclusion and migrants rights: Mexican seasonal workers in Canada. Citizenship Studies 8(1): 47-64.

Brannan T, John P, Stoker G (2006) Active citizenship and effective public services and programmes: How can we know what really works? Urban Studies 43(5/6): 9931008.

Boyd R (2006) The value of civility? Urban Studies 43(5/6): 863-878.

Brown BB, Perkins DD, Brown G (2004) Incivilities, place attachment and crime: Block and individual effects. Journal of Environmental Psychology 24: 359-371.

Cohen S (1985) Visions of Social Control. Cambridge: Polity Press.

Crawford A (2006) Fixing broken promises? Neighborhood wardens and social capital. Urban Studies 43(5/6): 957-976.

Félonneau ML (2004) Love and loathing of the city: Urbanophilia and urbanophobia, 
topological identity and perceived incivilities. Journal of Environmental Psychology 24: 43-52.

Flint J, Nixon J (2006) Governing neighbors: Anti-social behavior orders and new forms of regulating conduct in the UK. Urban Studies 43(5/6): 939-955.

Foucault M (1979) Discipline and punish: the birth of the prison. New York: Vintage.

Fyfe N (2005) Making space for "neo-communitarianism"? The third sector, state and civil society in the UK. Antipode 37(3): 536-557.

Fyfe N, Bannister J, Kearns A (2006) (In)civility and the city. Urban Studies 43(5/6): 853-861.

Goold BJ (2002) Privacy rights and public spaces: CCTV and the problem of the "unobservable observer". Criminal Justice Ethics Winter/Spring: 21-27.

Hunsberger CA, Gibson RB, Wismer SK (2005) Citizen involvement in sustainabilitycentered environmental assessment follow up. Environmental Impact Assessment Review 25: 609-627.

Kennett P, Forrest R (2006) The neighborhood in a European context. Urban Studies 43(4): 713-718.

Korte C (1980) Urban-nonurban differences in social behavior and social psychological models of urban impact. Journal of Social Issues 36(3): 29-51.

Koskela H (2000) "The gaze without eyes": Video-surveillance and the changing nature of urban space. Progress in Human Geography 24(2): 243-265.

Lee J (2006) Constructing race and civility in urban America. Urban Studies 43(5/6): 903-917.

Lees L (2004) The emancipatory city: urban (re)visions. In L Lees (Ed) The Emancipatory City? Paradoxes and Possibilities, 3-20. London: Sage.

Malone K (2002) Street life: youth, culture and competing uses of public space. Environment \& Urbanization 14(2): 157-168.

McCahill M (2002) The surveillance web: the rise of visual surveillance in an english city. Cullompton: Willan Publishing.

McCormick JG, Holland SM (2015) Strategies in use to reduce incivilities, provide security and reduce crime in urban parks. Security Journal 28(4): 374-391.

Medway D, Parker C, Roper S (2016) Litter, gender and brand: The anticipation of incivilities and perceptions of crime prevalence. Journal of Environmental Psychology 45: 135-144.

Milgram S (1970) The experience of living in cities: A psychological analysis. In FF Korten, SW Cook, JI Lacey (Eds), Psychology and the problems of society, 14611468. Washington, DC: American Psychological Association.

Norris C, Armstrong G (1999) The maximum surveillance society: the rise of CCTV as social control. Oxford, Berg.

Oc T, Tiesdell S (1997) The death and life of city centers. In T Oc, S Tiesdell (Eds) Safer City Centers. Reviving the Public Realm, 1-20. London: Paul Chapman.

Philips T, Smith P (2006) Rethinking urban incivility research: Strangers, Bodies and circulations. Urban Studies 43(5/6): 879-901.

Reisig MD, Cancino JM (2004) Incivilities in nonmetropolitan communities: The effects of structural constraints, social conditions and crime. Journal of Criminal Justice 32: 15-29.

Robin M, Police AM, Couty C (2007) Development of a scale of perceived environmental annoyances in urban settings. Journal of Environmental Psychology 27: 55-68.

Salcedo R (2003) When the global meets the local at the mall. American Behavioral Scientist 46(8): 1084-1103.

Sibley D (1995) Geographies of exclusion. London: Routledge.

Staeheli LA, Mitchell D (2006) USA's destiny? Regulating space and creating community 
Vol. 5, No. 2 Mugan: The Path towards a "Good City": A Discussion on (In) civility in American shopping malls. Urban Studies 43(5/6): 977-922.

Valera S, Guardia J (2014) Perceived insecurity and fear of crime in a city with lowcrime rates. Journal of Environmental Psychology 38: 195-205.

Wakefield A (2005) The public surveillance functions of private security. Surveillance and Society 2(4): 529-545.

Wilson JQ, Kelling G (1982) Broken windows. Atlantic Monthly 211: 29-38. 